\title{
MOLECULAR ABUNDANCES IN THE SGR A MOLECULAR CLOUD
}

\author{
Y. C. MINH $^{1}$, W. M. IRVINE ${ }^{2}$, and P. FRIBERG ${ }^{3,4}$ \\ 1 Inst. of Space Sci. and Astronomy, Daejon 305-348, Korea \\ 2 FCRAO, Univ. of Massachusetts, Amherst, MA 01003, USA \\ 3 Onsala Space Observatory, S-439 00 Onsala, Sweden \\ 4 Joint Astronomy Centre, Hilo, HI 96720, USA
}

\begin{abstract}
We have obtained column densities for $\mathrm{HCO}^{+}, \mathrm{HCO}, \mathrm{HCS}^{+}, \mathrm{C}_{3} \mathrm{H}_{2}$, $\mathrm{HC}_{5} \mathrm{~N}, \mathrm{SiO}, \mathrm{OCS}, \mathrm{HCOOH}, \mathrm{CH}_{3} \mathrm{CH}_{2} \mathrm{OH}$, and $\mathrm{CH}_{3} \mathrm{CCH}$ toward Sgr A. The frăctional abundance of $\mathrm{S}^{3} \mathrm{O}^{2}$ relative to molecular hydrogen in Sgr $\mathrm{A}$ is comparable to that for the Orion plateau, $\sim 10^{-7}-10^{-8}$, which may be a typical value for hot clouds. The abundances of $\mathrm{HCO}, \mathrm{CH} C H \mathrm{OH}$ and $\mathrm{CH} \mathrm{CCH}$ all appear to be enhanced relative to other molecular ${ }^{2}$ clouds suc as $^{3}$ Sgr B2.
\end{abstract}

The molecular abundances and chemistry of the Sgr A molecular cloud have not been as well characterized as those of Sgr B2, but the strong activities and shocks of the Galactic center could affect the clouds in Sgr A more efficiently because of their greater proximity. This may result in a unique chemistry of the Sgr A clouds, such as has been suggested from observations of $\mathrm{HCO}_{2}^{+}$(Minh et al. 1991a; Paper 1 ).

Data were obtained in 1988 June with the Swedish-ESO $15 \mathrm{~m}$ telescope in Chile. Telescope parameters and observing method were included in Paper 1. Observed molecules, transitions, and rest frequencies are listed in Table 1. We have obtained data for the clouds observed in $\mathrm{NH}_{3}$ (Gusten et al. 1981) and in $\mathrm{HCO}^{+}$(Paper 1). Column densities were determined assuming optically thin emission and an apparent background radiation temperature of $10 \mathrm{~K}$ ( $\mathrm{cf}$. Paper 1 and Minh et al. 1991b).

In Figure 1 we plot the fractional abundances relative to $H_{2}$ for th molecules observed toward M-0.13-0.08, and also those for TMC $-1^{2}$ and $\mathrm{Sgr}$ B2, and for Orion(KL) from the tabulations of Irvine et al. (1987), and Blake et al. (1987), respectively, for comparison. The fractional abundance of $\mathrm{SiO}$ at $\mathrm{Sgr} A$ is derived to be $\sim 10^{-7}-10^{-8}$ relative to molecular hydrogen which is similar to that of the Orion plateau. The high Sio abundance could be explained by high-temperature or shock chemistry (Ziurys et al. 1989). It is also possible, however, that an enhanced abundance of elemental Si comes from the disruption of silicat grains by shocks in the Galactic center region, which can lead naturall to an enhanced SiO abundance. 
TABLE 1. Observed molecules.

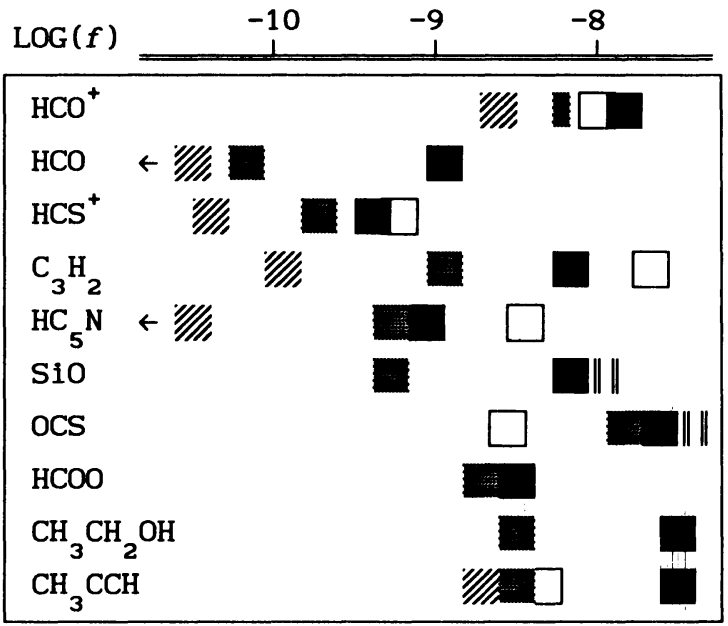

\begin{tabular}{|c|c|}
\hline Molecule (Trans.) & $\begin{array}{l}\text { Rest } \\
\text { Frequency } \\
(\mathrm{GHz})\end{array}$ \\
\hline $\mathrm{H}^{13} \mathrm{CO}^{+}(1-0)$ & 86.75429 \\
\hline $\mathrm{HC}^{18} \mathrm{O}^{+}(1-0)$ & 85.16226 \\
\hline $\begin{array}{l}\mathrm{HCO}\left(1_{01}-0_{00}{ }^{a}\right) \\
\mathrm{HCS}^{+}(2-1)\end{array}$ & $\begin{array}{l}86.67082 \\
85.34790\end{array}$ \\
\hline $\mathrm{C}_{3} \mathrm{H}_{2}\left(2_{12}{ }^{-1}{ }_{01}\right)$ & 85.33889 \\
\hline $\mathrm{HC}_{5} \mathrm{~N}(32-31)$ & 85.20135 \\
\hline SiO $(2-1)$ & 86.84700 \\
\hline${ }^{29} \mathrm{SiO}(2-1)$ & 85.75913 \\
\hline OCS $(7-6)$ & 85.13911 \\
\hline $\mathrm{HCOOH}\left(4_{14}-3_{13}\right)$ & 86.54613 \\
\hline $\mathrm{CH}_{3} \mathrm{CH}_{2} \mathrm{OH}\left(6_{06}-5_{15}\right)$ & 85.26547 \\
\hline $\mathrm{CH}_{3} \mathrm{CCH} \quad(\mathrm{J}=5-4 \mathrm{~K}=0)$ & 85.45730 \\
\hline$(\mathrm{J}=6-5 \quad \mathrm{~K}=0)$ & 102.54798 \\
\hline $\mathrm{CH}_{3} \mathrm{OH}\left(3_{1}-4{ }_{0} \mathrm{~A}^{+}\right)$ & 107.01385 \\
\hline
\end{tabular}

${ }^{a}$ For the $(3 / 2-1 / 22-1)$ trans.

SgrA SgrB2 TMC-1

Orion(KL)

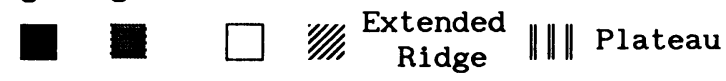

Figure. 1 Abundances relative to molecular hydrogen on a logarithmic scale for Sgr A, Sgr B2, TMC-1 and the Orion extended ridge and the plateau. Data for Sgr B2 and TMC-1 from Irvine et al. (1987), and for Orion(KL) from Blake et al. (1987).

The fractional abundances of several molecules observed here, in particular $\mathrm{HCO}, \mathrm{CH}_{3} \mathrm{CH}_{2} \mathrm{OH}$, and $\mathrm{CH}_{3} \mathrm{CCH}$, appear to be enhanced relative to values for other sources (Figure ${ }^{3} 1$ ). It is interesting that the production of $\mathrm{CH}_{3} \mathrm{CH}_{2} \mathrm{OH}$ and $\mathrm{CH}_{3} \mathrm{CCH}$ probably involves relatively hydrogenated species such as ${ }^{3} \mathrm{H}$ or $\mathrm{CH}$ (Millar et al. 1991; Millar \& Freeman 1984); this might suggest the influence of grain chemistry or high temperature reactions.

We conclude that a rich chemistry exists in Sgr A, which could partly be a result of the energetic processes of the Galactic center region, such as shocks, UV radiation, and also the possible interaction of the neutral and the ionized gas around the nucleus.

Blake G. A., Sutton E.C., Masson C.R., Phillips T.G., 1987, ApJ 315, 621 Gusten R., Walmsley C.M. Pauls T., 1981, A\&A 103, 197

Irvine W.M., Goldsmith P.F., Hjalmarson A., 1987, Interstellar Processes eds. D. J. Hollenbach, H. A. Thronson, Jr., D. Reidel, p. 561

Millar T. J., Freeman A., 1984, MNRAS 207, 405

Millar T.J., Herbst E., Charnley B., 1991, ApJ 369, 147

Minh Y.C., Brewer M.K., Irvine W.M., Friberg P., Johansson L.E. B., 1991a, A\&A 244, 470 ; Paper 1

Minh Y.C., Irvine W.M., Friberg P., 1991b, submitted to A\&A

Ziurys L.M., Friberg P., Irvine W.M., 1989, ApJ 343, 201 